\title{
The new design of a remote real time embedded medical platform
}

\section{Type of article: Conference abstract}

\author{
Ryad Temmar ${ }^{1}$, Mohamed Ouslim ${ }^{2}$, Mohammed \\ Mekri $^{3}$
}

${ }^{1}$ Ph.D student, LMSE laboratory, Department of Electronics, Faculty of Electrical Engineering, University of Science and Technology Oran, Oran, Algeria

${ }^{2}$ Professor, LMSE laboratory, Department of Electronics, Faculty of Electrical Engineering, University of Science and Technology Oran, Oran, Algeria ${ }^{3}$ Student, LMSE laboratory, Department of Electronics, Faculty of Electrical Engineering, University of Science and Technology Oran, Oran, Algeria ryad.temmar@univ-usto.dz

\begin{abstract}
:
Background: The aim of this work is to develop an electronic medical platform that enables us to monitor the physiological data of a patient and allows in cases of urgent problems to trigger an alarm remotely controlled by an expert to intervene quickly in case of emergency.

Methods: In this paper, we present the design of a new medical platform based on Arduino and its shields. This platform is made of two embedded electronic circuits. The first one that may be carried by the patient is implemented using the Arduino Uno and two expanded cards, namely the E-health and the XBee shields. This circuit reads periodically physiological data (ECG, temperature, spo 2 etc.) and wirelessly transmits them to the second circuit which is connected to the internet, based on the Arduino Ethernet electronic module and containing the XBee shield and an RFID module, as well as additional electronic circuits to report the critical situations, such as an LCD display and a buzzer to indicate an abnormal situation requiring local supervision. The patient is identified automatically by an RFID tag. Results: This platform was practically implemented as a final electronic product and tested. The results were very satisfactory as the embedded circuit was functioning correctly and we could upload and archive the collected data in real time in a specific database. A web server was also developed which gave remote access to the medical data of the patient making the control by a doctor possible for remote fast treatment.
\end{abstract}

Conclusion: The practical realization of our medical platform allowed us to test in real time remote monitoring of a patient's physiological data while identifying the patient with an RFID tag.

Keywords: Arduino, E-health, XBee, RFID, Web server

\section{Declaration of conflicts}

This article is selected from the abstract's book of the International Conference on Health Sciences and Medical Technologies,10-12 October 2017, Tlemcen, Algeria, ICHSMT' 17.

\section{Authors' biography}

No biography 
Medical Technologies Journal, Volume: 1, Issue: 3, July -September 2017, Pages: 55-56. DOI: https://doi.org/10.26415/2572-004X-vol1iss3p55-56

\section{References}

No references 